\title{
Lack of Direct Inhibition of Insulin Secretion by Exogenous Insulin in the Canine Pancreas
}

\author{
J. Stagner, E. Samols, K. Polonsky, and W. Pugh \\ Veterans Administration Medical Center and the Department of Medicine, University of Louisville School of Medicine, Louisville, \\ Kentucky 40202; Department of Medicine, University of Chicago, The Pritzker School of Medicine, Chicago, Illinois 60637
}

\section{Abstract}

To test whether insulin secretion is self-regulatory, canine pancreata were isolated and perfused in vitro and were infused with 0.3, 0.6, or $1.2 \mathrm{mU} / \mathrm{ml}$ exogenous insulin. Basal and argininestimulated concentrations of $\mathbf{C}$-peptide, glucagon, and somatostatin were measured. There were no significant differences between basal secretion nor the increment of arginine-stimulated secretion for each respective hormone at each exogenous insulin concentration.

The second preparation studied was a vascularly isolated, yet innervated, in situ perfused pancreas. Exogenous insulin (1 $\mathrm{mU} / \mathrm{kg}$ per $\mathrm{min}$ ) was infused "systemically"; the pancreas received no insulin. Endogenous pancreatic insulin and $\mathrm{C}$-peptide secretion was suppressed, while pancreatic glucagon secretion increased during systemic insulin infusion. No changes in pancreatic hormone secretion occurred after the sympathetic nerves were sectioned.

These results suggest that exogenous insulin does not directly suppress the B cell, but can suppress insulin secretion through an indirect neurally mediated, insulin-dependent nerve mechanism.

\section{Introduction}

That insulin secretion may be regulated by feedback inhibition by insulin itself has been suggested from studies in normal humans and from in vitro studies of perifused islet preparations and isolated perfused rat and canine pancreata (1-5). However, the evidence for a direct intraislet effect of insulin upon the B cell has been controversial owing to problems of experimental design, such as possible diffusion artifacts in isolated islet preparations, species differences between endogenous and exogenous insulin (6) and the necessity of measuring differences in endogenous insulin secretion during exogenous insulin infusion by indirect mathematical methods $(2,3)$. Therefore, depending upon the system examined and the experimental design, exogenous insulin has either been suggested to have no effect upon endogenous insulin release $(1,7-10)$ or to be inhibitory $(2,4$ $6,11,12)$. Reports concerning in vitro self-inhibition by insulin have thus been inconclusive $(1,2,6,8,9)$, although a recent report has suggested that exogenous insulin had no effect upon C-peptide secretion (10) from isolated rat islets. Reports from

Address reprint requests to Dr. Stagner, Research Service, VA Medical Center, 800 Zorn Avenue, Louisville, KY 40202.

Received for publication 7 April 1986.

This work was presented in part at the 7th International Congress of Endocrinology, Quebec City, Canada, 1-7 July 1984, and published in abstract form (1984. Excerpta Medica. 652:1309).

The Journal of Clinical Investigation, Inc.

Volume 78, November 1986, 1193-1198 in vivo studies have not alleviated the controversy as to whether the inhibition of endogenous insulin secretion by exogenous insulin is from a direct or an indirect effect upon the B cell, even though measurements of C-peptide in vivo have demonstrated clearly that during glucose clamping exogenous insulin inhibits endogenous insulin release $(4,5,7,11,12)$.

To determine whether the effects of exogenous insulin upon endogenous insulin secretion are the result of a direct or an indirect effect upon the B cell two models were examined. First, the canine pancreas was isolated and perfused in vitro (13) to test for possible direct effects of exogenous insulin upon the B cell. Changes in endogenous insulin secretion during the infusion of exogenous insulin were monitored by the measurement of Cpeptide (14). The second system examined was a vascularly isolated, yet innervated, perfused canine pancreas preparation. In this in situ innervated preparation, exogenous insulin could be administered specifically to the systemic circulation without contacting the pancreas itself. An inhibiting effect generated by systemically infused exogenous insulin upon both endogenous insulin and C-peptide release in this in situ preparation, would suggest that the inhibitory action was $(a)$ an indirect effect upon the B cell, as exogenous insulin was excluded from pancreatic circulation and $(b)$ neural in character.

\section{Methods}

Fasted mixed breed male German shepherd dogs weighing $25-30 \mathrm{~kg}$ were used as pancreas donors. Methods used in pancreatectomy and perfusion are described in detail elsewhere (13).

Exogenous porcine insulin (provided by Eli Lilly \& Co., Indianapolis, IN) was infused into the isolated in vitro pancreata at concentrations of $0.3,0.6$, or $1.2 \mathrm{mU} / \mathrm{ml}$ as separate perfusions for $45 \mathrm{~min}$ and then in combination with $10 \mathrm{mM}$ arginine for $10 \mathrm{~min}$. An arginine stimulation was used to more accurately test for endogenous insulin suppression, because a constant glucose concentration, i.e., clamp, was maintained throughout the study. Owing to the difficulties associated with determining endogenous insulin concentrations during exogenous insulin infusion, baseline $\mathrm{C}$-peptide concentrations and the increment of change from the respective baseline during an arginine stimulation were calculated as an index of the possible suppression of endogenous insulin secretion by exogenous insulin. Efflux concentrations of C-peptide (14), glucagon, and somatostatin (13) were determined by radioimmunoassay as previously described.

The in situ pancreas preparation, in which the pancreas was isolated vascularly yet remained innervated, was a modification of the methods described by Alteever et al. (15). Dogs were anesthetized with sodium pentobarbital, intubated with a cuffed endotracheal tube, and ventilated with room air. Animals were kept warm by means of a hot water warming blanket. Catheters were placed in the left and right femoral veins. Blood samples were removed from systemic blood for $\mathrm{pH}$, glucose, and hormone determinations through right femoral catheter, while glucose, bicarbonate, and other materials, such as insulin or pertechnetate-labeled albumin, were infused through the left femoral catheter.

A midline incision was made from the pelvis to the clavicle. The abdominal and thoracic cavities were held open by spreader clamps. 
Care was taken not to damage sympathetic and vagal trunks as they passed caudad through the diaphragm. The inferior mesenteric artery was ligated and a splenectomy was performed. The celiac and superior mesenteric arteries were located and the superior mesenteric artery was ligated. All branches of the celiac artery were ligated except the superior pancreaticoduodenal artery. The celiac artery was minimally exposed and cannulated with a flanged metal cannula. Great care was taken not to disturb the tissue between the celiac and superior mesenteric artery and any visible nerve tracts. The pancreas was perfused with oxygenated media as described elsewhere (13). The portal vein was then ligated and cannulated to drain the pancreas. A metal bar clamp was applied to the duodenum distal from the superior pancreaticoduodenal artery in order to prevent contamination of the pancreatic efflux by intestinal hormones and to provide support to the pancreas to prevent restriction of media flow and edema. Body temperature, $\mathrm{pH}$ and blood glucose levels were adjusted as required and monitored at 1-5-min intervals throughout the experiment. Pancreatic efflux temperature, flow rate, $\mathrm{pH}$, and perfusate pressure were monitored throughout the procedure as established for the in vitro pancreas (13).

After the insulin infusion portions of the experiments were concluded, the integrity of the nervous system was tested with a brief 3-5-min period of electrical stimulation $(20 \mathrm{~V}, 5 \mathrm{~Hz}, 1 \mathrm{~ms})$ of the cervical sympathetic trunks. The left and right sympathetic trunks were exposed and isolated distal from the heart. All tissue was stripped from the nerves for $2-3 \mathrm{~cm}$ in two areas for electrode placement and nerve sectioning. Pin electrodes or liquid junction electrodes were inserted into and around the nerves and secured in place, free of surrounding tissue. The left and right sympathetic trunks were sectioned anterior to the electrodes.

The degree of vascular isolation of the pancreas was determined by the injection of $1 \mathrm{mCi}$ of $99 \mathrm{mTc}$ pertechnetate labeled albumin into the peripheral circulation. After 15 min of equilibration, timed samples were taken both from the perfusate efflux and peripheral blood for comparison of radioactivity and a ratio was calculated. During the study, blood samples were obtained at 3-min intervals and were assayed for glucose concentration by means of a portable glucose analyzer (Yellow Springs Instruments, Yellow Springs, $\mathrm{OH}$ ). Based upon the glucose concentration, the glucose infusion rate was adjusted to maintain a glucose concentration or "glucose clamp" of $200 \mathrm{mg} / \mathrm{dl}$ in blood perfusing the body and brain (16). Glucose was clamped at this concentration in order to prevent central nervous glycopenia, which is known to activate the autonomic nervous system. Throughout both in situ and in vitro studies, the pancreatic perfusate glucose concentration was maintained at $88 \mathrm{mg} / \mathrm{dl}$ to facilitate the measurement of glucagon. Exogenous insulin was infused into the systemic circulation at $1 \mathrm{mU} / \mathrm{kg}$ per min for $15 \mathrm{~min}$ as a single infusion. Insulin and C-peptide measurements were performed upon simultaneously collected efflux and plasma samples to determine systemic insulin concentrations before and during systemic insulin infusions. Statistical differences of basal and arginine-stimulated insulin, C-peptide, glucagon, and somatostatin values between control periods (no exogenous insulin) and exogenous insulin infusions were determined by Student's $t$ test.

\section{Results}

Effect of exogenous insulin upon C-peptide, glucagon, and somatostatin secretion from the in vitro perfused pancreas. There were no significant differences in basal C-peptide concentrations between control perfusions (no exogenous insulin) and those results obtained from each respective exogenous insulin infusion (Table I). In addition, there were no differences between the arginine-stimulated increments of C-peptide secretion between controls and exogenous insulin infusions (Table I). There was a similar lack of suppression of basal and arginine-stimulated secretion of glucagon and somatostatin (Tables II and III, respectively) between controls and exogenous insulin infusions.

Effects of "systemic" exogenous insulin upon insulin, C-peptide, and glucagon secretion from the in situ perfused pancreas. The in situ pancreas preparation is unique in that the pancreas is excluded from the systemic vasculature and all blood borne metabolites, although neural connections to the body are maintained. That the neural connections were maintained and functional was established by electrically stimulating the cervical sympathetic nerves, which resulted in an increase in perfusion pressure $(7.3 \pm 3 \%$ change from basal, $n=10, P<0.05)$ resulting from pancreatic arteriolar contraction, a decrease in efflux flow rate $(-10.3 \pm 1 \%$ change, $n=10, P<0.05)$ and a decrease in the secretion of endogenous insulin $(-64 \pm 10 \%$ change, $n=10$, $P<0.0125)$. The relative systemic contamination or leakage of exogenous insulin into the pancreatic efflux was minimal as only $0.24 \pm 0.01 \%$ of the ${ }^{99} \mathrm{Tc}$-pertechnetate in vena caval blood was found in the pancreatic efflux $(n=10)$, yielding an estimated $0.9 \pm 0.12 \mu \mathrm{U} / \mathrm{ml}$ per min leakage calculated by:

$$
\frac{\text { cpm }^{99} \mathrm{Tc} \text { in pancreatic efflux }}{\mathrm{cpm}^{99} \mathrm{Tc} \text { in postcaval plasma }} \times \text { plasma insulin concentration }
$$

from a systemic insulin infusion of $1 \mathrm{mU} / \mathrm{kg}$ per min. Preinfusion systemic insulin concentrations were $3.4 \pm 1.7 \mu \mathrm{U} / \mathrm{ml}$ while concentrations of $366 \pm 88 \mu \mathrm{U} / \mathrm{ml}(n=8)$ were obtained from plasma samples drawn at the termination of systemic insulin infusions.

Table I. Effects of Exogenous Insulin upon Basal and Arginine-stimulated C-Peptide Secretion

\begin{tabular}{|c|c|c|c|c|c|c|c|c|c|c|}
\hline \multicolumn{8}{|c|}{ Exogenous insulin concentration } & \multirow{2}{*}{\multicolumn{3}{|c|}{ Statistical significance }} \\
\hline 0 & & $0.3 \mathrm{mU} / \mathrm{ml}$ & & $0.6 \mathrm{mU} / \mathrm{ml}$ & & $1.2 \mathrm{mU} / \mathrm{ml}$ & & & & \\
\hline Basal & Arg $\Delta C$-pep* & Basal & $\operatorname{Arg} \Delta C$-pep & Basal & $\operatorname{Arg} \Delta C$-pep & Basal & $\operatorname{Arg} \Delta C$-pep & $\begin{array}{l}\text { Insulin } \\
\text { infused }\end{array}$ & Basal & Arg $\Delta C$-pep \\
\hline$p M / m l$ & $p M / m l$ & $p M / m l$ & $p M / m l$ & $p M / m l$ & $p M / m l$ & $p M / m l$ & $p M / m l$ & $m U / m l$ & & \\
\hline \multirow[t]{3}{*}{$\begin{array}{l}0.171 \pm 0.03 \\
(n=7)\end{array}$} & $\begin{array}{l}0.143 \pm 0.03 \\
(n=7)\end{array}$ & $\begin{array}{l}0.167 \pm 0.016 \\
(n=5)\end{array}$ & $\begin{array}{l}0.145 \pm 0.04 \\
(n=5)\end{array}$ & $\begin{array}{l}0.191 \pm 0.044 \\
(n=5)\end{array}$ & $\begin{array}{l}0.175 \pm 0.032 \\
(n=5)\end{array}$ & $\begin{array}{l}0.216 \pm 0.033 \\
(n=5)\end{array}$ & $\begin{array}{l}0.132 \pm 0.061 \\
(n=5)\end{array}$ & $0-0.3$ & $P<0.475$ & $P<0.475$ \\
\hline & & & & & & & & $\begin{array}{r}0-0.6 \\
0.3-0.6\end{array}$ & $\begin{array}{l}P<0.35 \\
P<0.20\end{array}$ & $\begin{array}{l}P<0.25 \\
P<0.20\end{array}$ \\
\hline & & & & & & & & $\begin{array}{r}0-1.2 \\
0.3-1.2 \\
0.6-1.2\end{array}$ & $\begin{array}{l}P<0.20 \\
P<0.20 \\
P<0.25\end{array}$ & $\begin{array}{l}P<0.45 \\
P<0.40 \\
P<0.20\end{array}$ \\
\hline
\end{tabular}

\footnotetext{
* Arg $\Delta$ C-pep, arginine-stimulated increment of C-peptide increase above basal unstimulated C-peptide concentrations. Calculated as the integrated mean C-peptide
} concentration during a 10 -min arginine infusion minus the respective basal concentration. 
Table II. Effect of Exogenous Insulin upon Endogenous Basal and Arginine-stimulated Glucagon Secretion

\begin{tabular}{|c|c|c|c|c|c|c|c|c|c|c|}
\hline \multicolumn{8}{|c|}{ Exogenous insulin concentration } & \multirow{2}{*}{\multicolumn{3}{|c|}{ Statistical significance }} \\
\hline \multicolumn{2}{|l|}{0} & \multicolumn{2}{|c|}{$0.3 \mathrm{mU} / \mathrm{ml}$} & \multicolumn{2}{|c|}{$0.6 \mathrm{mU} / \mathrm{ml}$} & \multicolumn{2}{|c|}{$1.2 \mathrm{mU} / \mathrm{ml}$} & & & \\
\hline Basal & $\operatorname{Arg} \Delta G^{*}$ & Basal & $\operatorname{Arg} \Delta \mathrm{G}$ & Basal & $\operatorname{Arg} \Delta \mathrm{G}$ & Basal & $\operatorname{Arg} \Delta \mathrm{G}$ & $\begin{array}{l}\text { Insulin } \\
\text { infused }\end{array}$ & Basal & $\operatorname{Arg} \Delta \mathrm{G}$ \\
\hline$p g / m l$ & $p g / m l$ & $p g / m l$ & $p g / m l$ & $p g / m l$ & $p g / m l$ & $p g / m l$ & $p g / m l$ & $m U / m l$ & & \\
\hline $\begin{array}{l}56 \pm 13 \\
(n=10)\end{array}$ & $\begin{array}{l}229 \pm 61 \\
(n=10)\end{array}$ & $\begin{array}{l}71 \pm 13 \\
(n=7)\end{array}$ & $\begin{array}{l}166 \pm 52 \\
(n=7)\end{array}$ & $\begin{array}{l}74 \pm 17 \\
(n=7)\end{array}$ & $\begin{array}{l}282 \pm 126 \\
(n=7)\end{array}$ & $\begin{array}{l}65 \pm 12 \\
(n=6)\end{array}$ & $\begin{array}{l}190 \pm 65 \\
(n=6)\end{array}$ & $0-0.3$ & $P<0.20$ & $P<0.30$ \\
\hline & & & & & & & & $0-0.6$ & $P<0.20$ & $P<0.30$ \\
\hline & & & & & & & & $0.3-0.6$ & $P<0.40$ & $P<0.30$ \\
\hline & & & & & & & & $0-1.2$ & $P<0.25$ & $P<0.25$ \\
\hline & & & & & & & & $0.3-1.2$ & $P<0.50$ & $P<0.40$ \\
\hline & & & & & & & & $0.6-1.2$ & $P<0.35$ & $P<0.35$ \\
\hline
\end{tabular}

* Arg $\Delta \mathrm{G}$, Arginine-stimulated increment of glucagon increase above unstimulated glucagon concentrations.

Plasma glucose concentrations were maintained at $200 \pm 10 \mathrm{mg} /$ dl throughout the study.

As presented in Table IV, endogenous insulin and C-peptide secretion decreased in response to the systemic infusion of exogenous insulin $(P<0.0025$ and $P<0.05$, respectively). There was a concomitant increase $(P<0.0025)$ in glucagon secretion during systemic insulin infusions. The first $5 \mathrm{~min}$ of each $15-$ min systemic insulin infusion were not used for calculations of subsequent changes in endogenous insular hormone secretion, as that period was possibly required for a presumed central nervous effect to be transferred to the pancreas. As indicated in Table IV, 10 min after the termination of systemic insulin infusion, pancreatic insulin, C-peptide, and glucagon secretion returned to preinfusion levels. No changes in endogenous insulin or glucagon secretion in response to systemic exogenous insulin infusions were obtained after the sympathetic nerve trunks were severed.

\section{Discussion}

The hypothesis of autoregulation or self-inhibition by insulin has long been controversial. The disparity among reported results
(1-12) may be ascribed to the differences between the in vivo and in vitro systems examined, as well as the difficulties of interpretation presented by the attempt to measure endogenous insulin secreted during the presence of often large concentrations of exogenous insulin. Results obtained from isolated islets have the additional problem of interpretation imposed by possible diffusion artifacts, as the islets are not, perfused through the capillary bed. The direction of blood flow within the islet may have profound effects upon islet hormone secretion (17). Refinements in techniques, such as prelabeling intracellular insulin (9) and measurements of the labeled secreted product, as well as the measurement of cosecreted C-peptide $(10,14)$ may alleviate the conflict between reports of both inhibition (6) and no inhibition $(1,8,10)$ of endogenous insulin secretion by exogenous insulin in isolated islet preparations. Recent reports using the above prelabeling (9) and C-peptide measurements (10) have suggested that exogenous insulin may not inhibit endogenous insulin secretion. These reports further indicate that either exogenous insulin does not directly affect the B cell or that an indirect mechanism may be present that may not operate in isolated islet preparations.

Table III. Effects of Exogenous Insulin upon Endogenous Basal and Arginine-stimulated Somatostatin Secretion

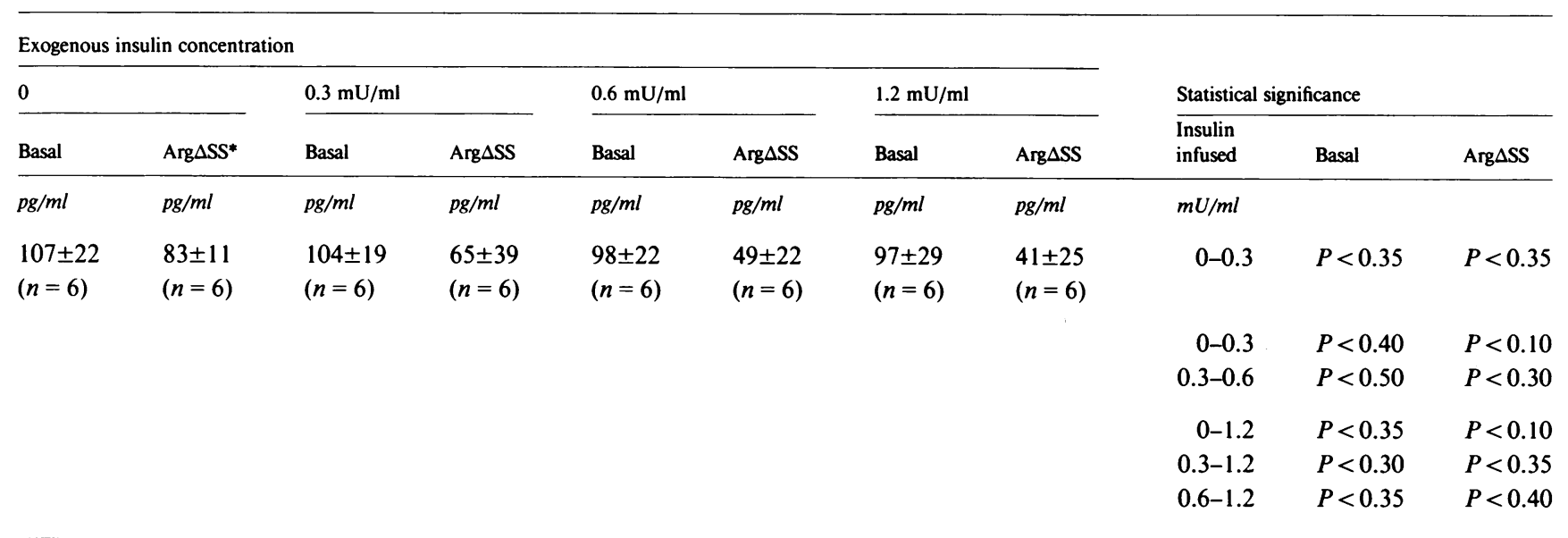

\footnotetext{
* Arg $\Delta \mathrm{SS}$, arginine-stimulated increment of somatostatin increase above basal unstimulated somatostatin concentrations.
} 
Table IV. Changes in Endogenous Insulin, C-Peptide and Glucagon Secretion by the Exposure of the Nervous System to Exogenous Insulin

\begin{tabular}{|c|c|c|c|c|c|}
\hline & \multirow[b]{2}{*}{ Basal (preinfusion) } & \multirow[b]{2}{*}{ Insulin infusion } & \multirow[b]{2}{*}{ Postinfusion } & \multicolumn{2}{|l|}{ Statistical significance } \\
\hline & & & & Preinfusion vs. infusion & Preinfusion vs. postinfusion \\
\hline \multicolumn{6}{|l|}{ Nerves intact } \\
\hline $\begin{array}{l}\text { Insulin }(\mu \mathrm{U} / \mathrm{ml}) \\
\quad n=9\end{array}$ & $186 \pm 17$ & $119 \pm 11$ & $178 \pm 20$ & $P<0.0025$ & $P<0.15$ \\
\hline C-peptide (pM/ml) & $0.942 \pm 0.116$ & $0.727 \pm 0.097$ & $0.895 \pm 0.123$ & $P<0.05$ & $P<0.35$ \\
\hline $\begin{array}{l}\text { Glucagon }(\mathrm{pg} / \mathrm{ml}) \\
n=7\end{array}$ & $287 \pm 64$ & $418 \pm 73$ & $272 \pm 72$ & $P<0.0025$ & $P<0.45$ \\
\hline \multicolumn{6}{|l|}{ Nerves cut } \\
\hline $\begin{array}{l}\text { Insulin }(\mu \mathrm{U} / \mathrm{ml}) \\
\quad n=5\end{array}$ & $71 \pm 11$ & $83 \pm 14$ & $79 \pm 10$ & $P<0.15$ & $P<0.20$ \\
\hline $\begin{array}{l}\text { Glucagon }(\mathrm{pg} / \mathrm{ml}) \\
\quad n=5\end{array}$ & $89 \pm 71$ & $56 \pm 35$ & $53 \pm 36$ & $P<0.20$ & $P<0.20$ \\
\hline
\end{tabular}

The technique of perfusing the isolated pancreas in vitro utilizes the normal vascular pathways, intraislet cellular relationships and local intrapancreatic nervous connections. However, various reports from studies of the isolated pancreas have suggested both no effect $(3,18)$ and inhibition of endogenous insulin secretion by the infusions of exogenous insulin $(2,19)$. Previous reports utilizing isolated perfused pancreas models have relied upon mathematical methods to measure endogenous insulin secretion that may be prone to misinterpretation $(2,3,20)$. We propose that indirect measurements of endogenous insulin secretion during the infusion of exogenous insulin, such as the measurement of $\mathrm{C}$-peptide and the increment of change from the respective basal concentration during a secretion stimulus, should more conclusively demonstrate the effect of insulin upon the $B$ cell $(14,19)$. The rationale of the arginine-stimulated increment (Arg $\Delta)$ as an indicator of the inhibition of endogenous C-peptide/insulin secretion by exogenous insulin, presumes that if endogenous secretion is inhibited, there should also be a diminution of stimulated secretion in proportion to the degree of inhibition.

Under the conditions imposed by the isolated perfused pancreas model, there were no changes in basal C-peptide, glucagon or somatostatin secretion (Tables I-III) in response to infusion of exogenous insulin concentrations of $0.3,0.6$, or $1.2 \mathrm{mU} / \mathrm{ml}$. There were no significant changes in the arginine-stimulated increment of change relative to the respective basal concentrations, as would be predicted if basal concentrations were not inhibited by exogenous insulin. Our previous report (13) concerning the lack of inhibition of glucagon and somatostatin by $50 \mathrm{mU} / \mathrm{ml}$ exogenous insulin is supported by both the present results and the work of others (21) and confirmed by the lack of inhibition of C-peptide/insulin secretion. The present results suggest that exogenous insulin does not directly inhibit endogenous C-peptide and insulin secretion in vitro and further suggest that the inhibition of endogenous insulin secretion by exogenous insulin in vivo may occur via an indirect mechanism, i.e., not through a direct insulin effect within the islet.

Recent reports, from experiments utilizing the glucose clamp technique in humans, have not further elucidated the question of the possible path or mechanism of endogenous insulin inhi- bition by exogenous insulin. The limitations of the human model do not allow one to discriminate between long loop or indirect effects and short loop or direct effects of insulin upon the B cell. Kraegen et al. (7) reported that they have found no evidence for either direct or indirect feedback of insulin upon the B cell, as varying C-peptide results were found depending upon whether exogenous insulin was infused concurrently with a glucose clamp. These investigators (7) concluded that a local pancreatic glucoseinsulin feedback loop dominated the short-term control of basal insulin secretion and that insulin self-regulation was not physiologically important. However, Klimes et al. (12) have reported that in Pima Indians the sensitivity of islets to exogenous insulin, i.e., reduction of C-peptide secretion, remained in subjects with marked peripheral glucoregulatory insensitivity to exogenous insulin. Moreover, other investigations using normal humans have reported decreases in endogenous $C$-peptide secretion during the infusion of exogenous insulin concurrently with normoglycemia maintained by a glucose clamp $(4,5,11)$. Although the reduction of $\mathrm{C}$-peptide secretion appeared to be related to the dose of exogenous insulin $(4,5,11)$, in normal individuals a dose sufficient to increase plasma insulin to $\sim 100 \mu \mathrm{U} / \mathrm{ml}$ above the baseline insulin concentration was found to produce no further reduction of C-peptide secretion (5). Near maximal suppression of hepatic glucose output was achieved at signifcantly lower doses of exogenous insulin (4). DeFronzo et al. (5) and Klimes et al. (12) concluded that the effects of insulin on the B cell noted above, were not mediated through the effects of insulin upon glucose metabolism.

The in situ vascularly isolated, innervated pancreas preparation is unique in that it permits the study of nervous effects on pancreatic islet function without directly exposing the islets to the agent being infused. It is most unlikely that the observed inhibition of insulin and C-peptide secretion and the concomitant increase in glucagon secretion by systemically infused exogenous insulin resulted from a direct effect upon the B cell, as little if any exogenous insulin reached the islet. The lack of change in endogenous insulin and glucagon secretion during a systemic exogenous insulin infusion after the sympathetic nerves were severed, strongly suggests the presence of an insulin-dependent nervous feedback mechanism. This conclusion is supported by 
the observation that sympathetic nerve stimulation produced a decrease in insulin secretion, as well a brief decrease in perfusate flow resulting in an increase in perfusion pressure, indicating the presence of functional sympathetic innervation of the pancreas, even though there was nearly complete vascular isolation. The present study suggests that the inhibition of endogenous insulin secretion by exogenous insulin described in vivo $(4,5$, $11,12)$ occurs by an indirect mechanism, possibly mediated through the nervous system. Although we have demonstrated an indirect nervous pathway, it should be noted that glucagon secretion from the in situ pancreas increased during the systemic infusion of exogenous insulin, whereas in vivo, both glucagon and C-peptide secretion decrease during exogenous insulin infusion $(11,12)$. This difference may be the result of an additional neural effect that was not observed in the in situ preparation.

It is not possible to further localize the site of regulation of the demonstrated neural pathway. The insulin-dependent regulatory site may reside either within the central nervous system or within the peripheral autonomic ganglia, or a combination of the two areas. Insulin receptors have been reported within the superior cervical sympathetic ganglion that may affect postganglionic nerve transmission (22). Insulin has been demonstrated to stimulate the release of norepinephrine in vivo (23). A recent report has suggested that pancreatic ganglia contain catecholamines, which in turn may release norepinephrine into the islet vasculature (24). There are also reports of insulin receptors present in the hypothalamus (25) and choroid plexus (26). Moreover, Smythe et al. (27) have reported that hypothalamic noradrenergic activity may affect hepatic glucose output in a reciprocal relationship. Glucose may provide a negative feedback signal to the hypothalamic noradrenergic system that may stimulate the release of hepatic glucose. However, the latter may be the result of neurally stimulated glucagon secretion (28). Smythe et al. (28) further report that exogenous insulin first reduces central nervous glucose utilization to suppress hypothalamic noradrenergic activity within $10 \mathrm{~min}$ of infusion. After 20-30 min, noradrenergic activity was elevated. Exogenous insulin therefore may act as signal to the basal medial hypothalamus and exert rapid effects on hypothalamic noradrenergic nerve activity by promoting cellular potassium shifts to alter nerve action potentials, rather than by increasing brain glucose uptake and metabolism (26-29). Whether the neural mechanism demonstrated in situ is the same mechanism as in in vivo models has not been established because of the difference in glucagon secretion (decreased in vivo; increased in vitro) between these two systems.

In summary, the present study strongly suggests that exogenous insulin does not directly suppress the B cell. Exogenous insulin can inhibit endogenous insulin secretion by an indirect neurally mediated, insulin-dependent feedback mechanism. The pharmacological dissection and classification of this nerve-mediated insulin regulatory system warrants further study.

\section{Acknowledgments}

The authors wish to acknowledge the technical assistance of J. Akin, C. Carpenter, M. Lewis, M. Mauch, V. Weis, and S. James for preparation of the manuscript.

This work was supported by the merit review grant program of the Veterans Administration and grants AM-13842 and AM-20595 from the National Institutes of Health.

\section{References}

1. Marincola, F., W. Frank, W. Clark, M. Douglas, and R. Merrell. 1983. The independence of insulin release and ambient insulin in vitro. Diabetes. 32:1162-1167.

2. Iversen, J., and D. W. Miles. 1971. Evidence for a feedback inhibition of insulin on insulin secretion in the isolated, perfused canine pancreas. Diabetes. 20:1-9.

3. Kawai, K., and R. H. Unger. 1982. Inhibition of glucagon secretion by exogenous glucagon in the isolated, perfused dog pancreas. Diabetes. 31:512-515.

4. Waldhausl, W. K., G. Gasic, P. Bratusch-Marrain, A. Korn, and P. Nowotny. 1982. Feedback inhibition by biosynthetic human insulin of insulin release in healthy human subjects. Am. J. Physiol. 243:E476482.

5. DeFronzo, R. A., C. Binder, J. Wahren, P. Felig, E. Ferrannini, and O. Faber. 1981. Sensitivity of insulin secretion to feedback inhibition by hyperinsulinaemia. Acta Endocrinol. 98:81-86.

6. Sodoyez, J. C., F. Sodoyez-Goffaux, and P. P. Foa. 1969. Evidence for an insulin-induced inhibition of insulin release by isolated islets of Langerhans. Proc. Soc. Exp. Biol. Med. 130:568-571.

7. Kraegen, E. W., L. Lazarus, and L. V. Campbell. 1983. Failure of insulin infusion during euglycemia to influence endogenous basal insulin secretion. Metabab. Clin. Exp. 32:622-627.

8. Malaisse, W. J., F. Malaisse-Lagae, P. E. Lacy, and P. H. Wright. 1967. Insulin secretion by isolated islets in presence of glucose, insulin and anti-insulin serum. Proc. Soc. Exp. Biol. Med. 124:497-500.

9. Schatz, H., and E. F. Pfeiffer. 1977. Release of immunoreactive and radioactively prelabelled endogenous (pro-) insulin from isolated islets of rat pancreas in the presence of exogenous insulin. J. Endocrinol. 74:243-249.

10. Beischer, W., W. Michael, B. Maier, M. Maas, and L. Keller. 1983. The poor evidence for a direct feedback inhibition of insulin on its secretion. Diabetologia. 25:139. (Abstr.)

11. Asplin, C. M., T. L. Paquette, and J. P. Palmer. 1981. In vivo inhibition of glucagon secretion by paracrine beta cell activity in man. J. Clin. Invest. 68:314-318.

12. Klimes, I., M. Nagulesparan, B. Vasquez, H. Hidaka, and R. H. Unger. 1984. Normal insulin sensitivity of the islets of Langerhans in obese subjects with resistance to its glucoregulatory actions. Diabetes. 33:305-310.

13. Weir, G. C., E. Samols, S. Loo, Y. C. Patel, and K. H. Gabbay. 1979. Somatostatin and pancreatic polypeptide secretion. Effects of glucagon, insulin and arginine. Diabetes. 28:35-40.

14. Polonsky, K., J. Jaspan, W. Pugh, D. Cohen, M. Schneider, T. Schwartz, A. R. Moosa, H. Tager, and A. H. Rubenstein. 1983. Metabolism of C-peptide in the dog. In vivo demonstration of the absence of hepatic extraction. J. Clin. Invest. 72:1114-1123.

15. Alteveer, R. J., M. J. Jaffe, and J. VanDam. 1979. Hemodynamics and metabolism of the in vivo vascularly isolated canine pancreas. Am. J. Physiol. 363:E626-632.

16. Ward, W. K., D. C. Bolgiano, B. McKnight, J. B. Halter, and D. Porte, Jr. 1984. Diminished B cell secretory capacity in patients with noninsulin-dependent diabetes mellitus. J. Clin. Invest. 74:1318-1328.

17. Stagner, J. I., and E. Samols. 1986. Retrograde perfusion as a model for testing the relative effects of glucose versus insulin on the Acell. J. Clin. Invest. 77:1034-1037.

18. Grodsky, G. M., R. Fanska, and F. G. Schmid. 1973. Evaluation of the role of exogenous insulin on phasic insulin secretion. Diabetes. 22:256-263.

19. Stagner, J., E. Samols, and K. Polonsky. 1984. Lack of a direct effect of exogenous insulin on the B-cell. Excerpta Medica. 652:1309. (Abstr.)

20. Rappaport, A. M., S. Ohira, J. A. Codding, G. Empey, A. Kalnins, B. J. Lin, and R. E. Haist. 1971. Effects on insulin output and on pan- 
creatic blood flow of exogenous insulin infusion into an in situ isolated portion of the pancreas. Endocrinology. 91:168-176.

21. Grodsky, G. M., G. H. Epstein, R. Fanska, and J. H. Karam. 1977. Pancreatic action of the sulfonylureas. Fed. Proc. 36:2714-2719.

22. Haring, H. U., and D. Kirsch. 1980. Insulin-binding and insulin action on CAMP levels in the superior cervical ganglion of the rat. Diabetologia. 19:281. (Abstr.)

23. Rowe, J. W., J. B. Young, K. L. Minaker, A. L. Stevens, J. Pallota, and L. Landsberg. 1981. Effect of insulin and glucagon infusion on sympathetic nervous system activity in normal man. Diabetes. 30:219-225.

24. Baetens, D., M. Vasko, R. H. Unger, and L. Orci. 1985. Ultrastructural detection of granulated cells in the autonomic ganglia of the rat pancreas. Diabetologia. 28:841-846.

25. Van Houten, M., B. I. Posner, B. W. Kipriwa, and J. R. Brawer.
1980. Insulin binding sites localized to nerve terminals in rat median eminance and arcuate nucleus. Science (Wash. DC). 207:1081-1083.

26. Baskin, D. G., B. Brewitt, D. A. Davidson, E. Coy, T. Paquette, D. C. Figlewicz, T. K. Lewellen, M. K. Graham, S. G. Woods, and D. M. Dorsa. 1986. Quantitative autoradiographic evidence for insulin receptors in the choroid plexus of the rat brain. Diabetes. 35:246-249.

27. Smythe, G. A., H. S. Grunstein, J. E. Bradshaw, M. V. Nicholson, and P. J. Compton. 1984. Relationships between brain noradrenergic activity and blood glucose. Nature (Lond.). 308:65-67.

28. Smythe, G. A., J. E. Bradshaw, H. S. Grunstein, and L. H. Storlien. 1984. Insulin as a signal to the brain. Excerpta Medica. 652:1301. (Abstr.)

29. Cane, P., R. Artal, and R. N. Bergman. 1986. Putative hypothalamic glucoreceptors play no essential role in the response to moderate hypoglycemia. Diabetes. 35:268-277. 